\title{
Um Dia na Vida de Irmãos que Cuidam de $\operatorname{Irmãos}^{1}$
}

\author{
Letícia Lovato Dellazzana ${ }^{2}$ \\ Lia Beatriz de Lucca Freitas \\ Universidade Federal de Rio Grande do Sul
}

\begin{abstract}
RESUMO - O objetivo deste artigo é descrever a rotina de adolescentes de baixa renda que cuidam de seus irmãos. Participaram do estudo 20 adolescentes de 12 a 16 anos. Foi utilizada uma ficha de dados sociodemográficos, genograma familiar e entrevista semiestruturada sobre um dia de suas vidas. Organizaram-se as atividades relatadas em cinco categorias: cuidado pessoal, cuidado dos irmãos, domésticas, escolares e de lazer. A partir dessas atividades dividiram-se os participantes em três grupos: responsáveis pelo cuidado dos irmãos, ajudam suas mães e sem essas atividades. Os resultados indicaram que adolescentes de ambos os sexos cuidam dos irmãos, mas são as meninas que mais assumem tarefas domésticas. Quando responsabilizados pelo cuidado, suas atividades escolares e de lazer são prejudicadas.
\end{abstract}

Palavras-chave: cuidado entre irmãos; adolescentes; famílias de baixa renda.

\section{A Day in the Life of Siblings who Take Care of Younger Siblings}

\begin{abstract}
The objective of this paper is to describe the daily routines of low-income adolescents, focusing particularly on those who look after their siblings. The description is based on a study conducted with 20 adolescents of 12 to 16 years of age. The instruments were: a record of socio-demographic data, a family genogram, and a semi-structured interview about a typical day. The activities described were organized into: personal care, sibling care, domestic tasks, school tasks, and leisure. The participants were divided into three groups based on type of care: those responsible for sibling care, those who helped their mothers with sibling care, and those without such responsibilities. The results showed that adolescents of both sexes took care of siblings, but females were more likely to take on domestic chores. School and leisure activities of adolescents were prejudiced when they were responsible for care.
\end{abstract}

Keywords: sibling care; adolescents; low-income families.

Os irmãos desempenham papéis de cuidadores, amigos e figuras de suporte ao longo de toda a vida (Conger, Stocker \& McGuire, 2009; Perez, 2002; Teti, 2001; Zukow, 2002). Através da mútua socialização, de comportamentos de ajuda nas tarefas, de atividades cooperativas e do simples companheirismo, irmãos causam uma grande influência uns na vida dos outros (Silveira, 2002). Além de terem uma participação importante no processo de socialização, os irmãos mais velhos podem assumir o papel de cuidadores formais de seus irmãos mais novos. Neste caso, elementos do relacionamento progenitores-filhos são incorporados à relação entre irmãos (Furman, Rahe \& Hartup, 1979).

Desde o trabalho de Weisner e Gallimore (1977), sabe-se que, em algumas culturas, as crianças assumem a tarefa de cuidar de seus irmãos menores como parte de sua rotina (East, Weisner \& Slonim, 2009; Hafford, 2010). Enquanto alguns grupos sociais priorizam a autonomia e a privacidade entre os irmãos, outros exigem que eles participem conjuntamente nas obrigações domésticas - as quais incluem o cuidado das

1 Este artigo é baseado em parte da Dissertação de Mestrado da primeira autora, realizada sob orientação da segunda. Esta Dissertação de Mestrado foi desenvolvida no Programa de Pós-Graduação em Psicologia da Universidade Federal de Rio Grande do Sul. Agradecemos ao Programa de Atenção Integral à Família de Porto Alegre.

2 Endereço para correspondência: Universidade Federal do Rio Grande do Sul, Instituto de Psicologia, LAPEGE - Laboratório de Psicologia e Epistemologia Genética, Rua Ramiro Barcelos, 2600 - sala 118, Bairro Santana, Porto Alegre, RS, CEP: 90035-003. Fone/Fax: (51) 3308-5314.E-mail: leticiadellazzana@gmail.com crianças mais novas - bem como nas atividades da comunidade (Carreño \& Avila, 2002; Szinovacz, 2007; Weisner,1987).

Cuidar significa dar segurança ou apoio para um indivíduo diferenciado, concebido como mais fraco ou mais vulnerável. O sistema de cuidado inclui comportamentos cujas funções são dar suporte emocional e material a uma outra pessoa, além de garantir o seu bem-estar (Stewart \& Marvin, 1984). É mais provável que o cuidado entre irmãos ocorra quando o irmão mais velho reconhece algum perigo para os demais. Além disso, quando há um sistema familiar cooperativo, também é possível que surjam situações de cuidado entre irmãos. Para Stewart e Marvin, a idéia de que o irmão mais velho age como uma figura de apego secundária para a criança representa um claro afastamento do foco usual no vínculo mãe-bebê nas culturas ocidentais.

Em sociedades agrárias, os irmãos cuidadores fazem mais do que suprir as necessidades biológicas imediatas e divertir os irmãos mais novos (Zukow, 2002; Weisner, 1987). Eles são mediadores da cultura, visto que apresentam a seus irmãos formas de agir e conhecer, através de estilos únicos de interação. Nesse cenário, os progenitores valorizam a assistência pouco especializada da criança na produção de comida e de artefatos e, especialmente, sua assistência no cuidado de irmãos mais novos. Assim, preparar uma criança para se tornar um membro competente de uma cultura agrária requer um conjunto diferente de prioridades daquele necessário para os membros de uma cultura tecnológica. A interdependência, por exemplo, é crucial para a sobrevivência de toda a família nas sociedades agrárias, enquanto a 
independência é priorizada nas tecnológicas. Desta forma, o grau no qual as crianças participam do cuidado de irmãos mais novos reflete diretamente a importância de dividir essa tarefa para o bem-estar econômico da família.

O cuidado entre irmãos também acontece nas sociedades industrializadas, tipicamente em situações esporádicas (Cicirelli, 1994). Os irmãos mais velhos ensinam os mais jovens informalmente e as atividades de cuidado não fazem parte da rotina familiar estabelecida. Nessas sociedades, as famílias tendem a ter menos filhos e, além disso, há uma maior diferença de idade entre eles, o que torna mais fácil, para os pais, focalizar recursos e atenção em cada um dos filhos.

Aspectos culturais, políticos e econômicos da sociedade influenciam o relacionamento entre irmãos. Apesar de diferentes formas de organização familiar serem possíveis, em uma mesma sociedade (Tudge, 2008), o cuidado não-parental é a norma ou, pelo menos, uma forma significativa de cuidado em muitas culturas (Carreño \& Avila, 2002; Szinovacz, 2007; Weisner \& Gallimore, 1977). A presença de muitos filhos e um intervalo amplo de idade entre o irmão mais velho e os mais novos favorecem a utilização do primogênito como recurso para cuidar dos irmãos mais novos (Ferreira, 1991; Furman, Rahe \& Hartup, 1979). Esses estudos sugerem que a composição e o tamanho da família são fatores determinantes para que o cuidado entre irmãos se torne formal.

As pesquisas sobre esse tema indicam que cuidados formais dispensados por irmãos mais velhos são mais facilmente encontrados em famílias com muitos filhos, quando os filhos mais velhos são do sexo feminino e no momento em que o filho mais novo já pode se locomover sozinho (Dunn, 1983; Ferreira, 1991; Lordelo \& Carvalho, 1999). Além disso, o nível socioeconômico também influencia na ocorrência de cuidado entre irmãos (Burton, 2007; Fulighi, Hughes \& Way, 2009). Em famílias numerosas e de baixo nível socioeconômico, a ausência de um dos progenitores pode exigir que os irmãos mais novos sejam cuidados pelos mais velhos (Dahlblom, Herrara, Pena \& Dahlgren, 2009; East, Weisner \& Slonim, 2009; Hafford, 2010; Poletto, Wagner \& Koller, 2004).

As famílias de baixa renda possuem características específicas, pois precisam desenvolver estratégias de sobrevivência compatíveis com suas condições de existência (Amazonas, Damasceno Terto \& Silva, 2003; Pires, Matos, Cerqueira, Figueiredo \& Souza, 2004). Todos os membros da família participam da manutenção do grupo tanto no que se refere ao provimento das necessidades básicas quanto ao cuidado com seus membros. Por essa razão, essas famílias promovem uma relação de solidariedade, por meio da qual conseguem garantir a qualidade de vida de cada um. A lógica da solidariedade opõe-se à lógica do individualismo, pois "reordena valores e subordina realizações pessoais a interesses ou necessidades do grupo familiar" (Amazonas \& cols., 2003, p. 13). Assim, nessas famílias, é comum que os cuidados com as crianças sejam compartilhados por todos os membros.

Segundo Lordelo e Carvalho (1989), a literatura aponta efeitos positivos no comportamento de cuidado entre crianças. Para a criança que cuida, esses efeitos são expressos através do treinamento de funções importantes para a vida adulta, por exemplo, o desenvolvimento da cognição e da responsabilidade (Romich, 2007). Para a criança que é cuidada, os efeitos são: (a) influência positiva na relação mãe-filho; (b) desenvolvimento da autonomia; e (c) preparação para relações com pares. Os efeitos negativos estão relacionados à formação da personalidade, pelo menos, quando as crianças são cuidadas predominantemente por outras crianças.

O estudo de Ferreira (1991) mostrou que os irmãos que cuidam de seus irmãos na ausência dos pais podem ser considerados agentes socializadores competentes, pois eles estimulam e facilitam a participação das crianças nas atividades da vida diária. Essa pesquisa mostrou que, entre todas as tarefas domésticas que os filhos responsáveis realizam, a atividade na qual eles encontram mais satisfação é cuidar dos irmãos.

Um estudo realizado com meninas de famílias de baixo nível socioeconômico (Poletto \& cols., 2004) indicou que a relação entre elas e seus irmãos parece ser saudável. Todavia, apesar dessa relação possibilitar às meninas a expressão de sua capacidade de cuidar, muitas vezes, em função disto, elas perdem sua condição de criança. Assim, apesar de darem conta das demandas por elas vivenciadas, os riscos a que estão expostas são constantes e muitas situações podem causar dano psicológico e/ou emocional. Soma-se a isso o fato de que elas nem sempre possuem apoio e recursos suficientes para lidarem com todos esses riscos.

Ainda que o cuidado entre irmãos não tenha sido suficientemente estudado (Zukow, 2002; Perez, 2002), essa situação tem sido apontada como um fator importante no desenvolvimento infantil (Dunn, 1983; Ferreira, 1991; Stewart \& Marvin, 1984; Weisner \& Gallimore, 1977). Estudos sobre o desenvolvimento da brincadeira, da cognição e da linguagem da criança indicaram um efeito positivo do cuidado entre irmãos, mesmo em cenários tecnológicos (Zukow, 2002). Considerando-se que em famílias de baixo nível socioeconômico o cuidado entre irmãos tende a acontecer com maior frequência, o objetivo deste artigo foi descrever a rotina de adolescentes de famílias de baixa renda. Para tanto, foram investigadas atividades de cuidado pessoal e alimentação, de cuidado com irmãos menores, tarefas domésticas, atividades escolares e de lazer.

\section{Método}

\section{Participantes}

Participaram deste estudo 20 adolescentes de famílias de baixa renda, em situação de vulnerabilidade social, sendo 16 do sexo feminino e quatro do sexo masculino. Os critérios de inclusão na amostra foram: (a) idade entre 12 e 18 anos e (b) que as famílias dos adolescentes fossem atendidas por programas sociais da Fundação de Assistência Social e Cidadania da Prefeitura Municipal de Porto Alegre.

\section{Instrumentos}

$\mathrm{Na}$ coleta de dados, foram utilizados os seguintes instrumentos: (a) ficha de dados sociodemográficos, a qual havia sido previamente preenchida pelos psicólogos que acompanhavam as famílias dos participantes, da qual foram selecionados os seguintes dados: data de nascimento, idade e escolaridade do adolescente, número total de irmãos e renda 
familiar; (b) genograma familiar, o qual buscou verificar diferentes aspectos da configuração familiar; (c) entrevista semiestruturada sobre um dia de vida, cujo objetivo foi investigar a rotina de um dia de vida do adolescente. As temáticas investigadas foram: higiene pessoal, refeições, atividades escolares e tempo livre. Os adolescentes envolvidos com o cuidado dos irmãos menores mencionaram as atividades de cuidado e ou domésticas espontaneamente, na medida em que relataram sua rotina diária. Inicialmente, foi-lhe dito: "Agora, preciso saber tudo o que tu fazes durante um dia comum de tua vida, desde a hora que tu acordas até a hora em que tu vais dormir." Na medida em que o participante narrava o seu dia, formulavam-se outras perguntas. Por exemplo, se o adolescente dizia: Quando acordo, tomo café. Então, perguntava-se: A que horas tu acordas? Quem prepara o café na tua casa?

\section{Procedimentos}

Os adolescentes foram convidados a participar da pesquisa e uma vez confirmado o interesse foi agendado um encontro para a realização da coleta de dados. Todos os adolescentes convidados aceitaram participar da pesquisa e foram entrevistados individualmente no Módulo de Assistência Social ou na entidade conveniada à prefeitura mais próxima de sua residência. As entrevistas foram gravadas e posteriormente transcritas para análise. O projeto de pesquisa foi aprovado pelo Comitê de Ética em Pesquisa do Instituto de Psicologia da Universidade Federal do Rio Grande do Sul. Todos os participantes, bem como seus responsáveis legais, assinaram o Termo de Consentimento Livre e Esclarecido.

A ficha de dados sociodemográficos e o genograma familiar foram utilizados para a caracterização da amostra. Para analisar os dados coletados na entrevista, foi utilizada análise de conteúdo (Laville \& Dionne, 1999).

\section{Resultados}

A partir da leitura dos relatos sobre um dia de vida dos adolescentes, identificaram-se atividades típicas de um dia de semana comum. Foram construídas cinco categorias de análise: (a) atividades de cuidado pessoal e alimentação, (b) atividades de cuidado dos irmãos menores, (c) atividades domésticas, (d) atividades escolares e (e) atividades de lazer.

Os participantes foram divididos em três grupos considerando-se a presença ou não da situação de cuidado entre irmãos, bem como o nível de responsabilidade e de intensidade do cuidado dispensado: Grupo 1 - adolescentes responsáveis pelo cuidado de seus irmãos menores; Grupo 2 - adolescentes que ajudam suas mães ${ }^{3}$ no cuidado de seus irmãos menores e Grupo 3 - adolescentes que não realizam atividades de cuidado de seus irmãos menores.

3 Quanto às famílias reconstituídas e nucleares, todos os participantes do estudo utilizaram a expressão "ajudar a mãe" ao mencionarem atividades de cuidado dos irmãos menores e atividades domésticas.

Tabela 1. Descrição das características familiares e escolares dos participantes

\begin{tabular}{|c|c|c|c|c|c|c|c|}
\hline Participante* & $\begin{array}{l}\text { Idade } \\
\text { (anos/meses) }\end{array}$ & Família+ & $\begin{array}{l}N^{o} \text {. de } \\
\text { Filhos }\end{array}$ & $\begin{array}{c}N^{o} . \text { em } \\
\text { casa }\end{array}$ & Ordem** & Série++ & $\begin{array}{c}\mathbf{N}^{0} \text {. de } \\
\text { Rep. }+++\end{array}$ \\
\hline \multicolumn{8}{|l|}{ Grupo 1} \\
\hline Af & $12 / 8$ & monoparental & 4 & 3 & $2^{a}$ & $2^{\mathrm{a}}$ & 3 \\
\hline $\mathrm{Bf}$ & $12 / 9$ & monoparental & 7 & 4 & $3^{a}$ & $4^{\mathrm{a}}$ & 3 \\
\hline $\mathrm{Cm}$ & $13 / 6$ & monoparental & 6 & 6 & $2^{o}$ & $2^{\mathrm{a}}$ & 2 \\
\hline $\mathrm{Ff}$ & $14 / 11$ & reconstituída & 5 & 4 & $2^{\mathrm{a}}$ & $5^{\mathrm{a}}$ & 3 \\
\hline $\mathrm{Gm}$ & $14 / 11$ & reconstituída & 6 & 6 & $1^{\mathrm{o}}$ & $4^{\mathrm{a}}$ & 3 \\
\hline If & $16 / 7$ & monoparental & 9 & 6 & $1^{a}$ & $5^{\mathrm{a}}$ & 3 \\
\hline Jf & $16 / 9$ & reconstituída & 6 & 5 & $3^{a}$ & $6^{\mathrm{a}}$ & 3 \\
\hline \multicolumn{8}{|l|}{ Grupo2 } \\
\hline $\mathrm{Kf}$ & $12 / 2$ & nuclear & 5 & 4 & $3^{a}$ & $5^{\mathrm{a}}$ & 2 \\
\hline Lf & $12 / 6$ & nuclear & 3 & 3 & $3^{a}$ & $5^{\mathrm{a}}$ & 2 \\
\hline $\mathrm{Nf}$ & $13 / 0$ & monoparental & 5 & 5 & $2^{a}$ & $6^{\mathrm{a}}$ & 0 \\
\hline Df & $13 / 10$ & monoparental & 7 & 7 & $1^{a}$ & $5^{\mathrm{a}}$ & 1 \\
\hline Qm & $13 / 11$ & nuclear & 8 & 8 & $2^{\mathrm{a}}$ & $7^{\mathrm{a}}$ & 1 \\
\hline Ef & $14 / 7$ & nuclear & 5 & 4 & $2^{a}$ & $5^{\mathrm{a}}$ & 3 \\
\hline Of & $15 / 4$ & monoparental & 5 & 5 & $1^{a}$ & $8^{\mathrm{a}}$ & 0 \\
\hline $\mathrm{Pf}$ & $15 / 7$ & monoparental & 6 & 6 & $2^{a}$ & $7^{\mathrm{a}}$ & 1 \\
\hline Hf & $16 / 0$ & monoparental & 7 & 7 & $3^{a}$ & $6^{\mathrm{a}}$ & 3 \\
\hline \multicolumn{8}{|l|}{ Grupo 3} \\
\hline $\mathrm{Mm}$ & $13 / 2$ & monoparental & 8 & 2 & $8^{\circ}$ & $5^{\mathrm{a}}$ & 2 \\
\hline $\mathrm{Rf}$ & $15 / 10$ & nuclear & 6 & 3 & $5^{a}$ & $8^{\mathrm{a}}$ & 0 \\
\hline $\mathrm{Sf}$ & $16 / 9$ & reconstituída & 4 & 4 & $1^{a}$ & $6^{\mathrm{a}}$ & 2 \\
\hline $\mathrm{Tf}$ & $16 / 10$ & nuclear & 6 & 3 & $3^{a}$ & $8^{\mathrm{a}}$ & 0 \\
\hline
\end{tabular}

* A primeira letra corresponde ao participante e a segunda corresponde ao sexo do participante ( $\mathrm{f}=$ feminino; $\mathrm{m}=$ masculino); + Configuração familiar; ** Ordem de nascimento entre os irmãos; ++ Todos os participantes frequentam o Ensino Fundamental; +++ Número de reprovações. 
Como todas as famílias dos adolescentes entrevistados eram acompanhadas através de programas sociais, elas recebiam uma bolsa cujo valor máximo era de R\$ 200,00. A renda suplementar era proveniente de algum tipo de trabalho realizado pelos progenitores dessas famílias. Desta forma, a renda das famílias variava entre $\mathrm{R} \$ 200,00$ e $\mathrm{R} \$ 500,00$ mensais. No Grupo 1, cinco progenitores exerciam algum tipo de atividade remunerada, enquanto que no Grupo 2 esse número era de oito. No Grupo 3, três progenitores trabalhavam.

$\mathrm{Na}$ categoria atividades de cuidado pessoal e alimentação, foram incluídas as seguintes situações: tomar banho, escovar os dentes, tomar café da manhã, almoçar, tomar café da tarde e jantar. Todos os adolescentes dos três grupos realizam, em média, quatro refeições por dia. Em relação à higiene pessoal, a maioria dos adolescentes toma dois banhos por dia, um pela manhã e outro à noite. Esta foi a única categoria na qual não foram encontradas diferenças entre os três grupos. A seguir são apresentados os resultados encontrados nas demais categorias, em cada um dos grupos.

\section{Atividades do Grupo 1}

As atividades de cuidado dos irmãos menores citadas foram: servir o café da manhã, o almoço, o café da tarde, a janta, dar mamadeira, vestir e pentear, levar e buscar na escola e na atividade extraclasse, dar banho, colocar os irmãos para que eles assistam televisão, fazer dormir, trocar as fraldas e cuidar dos irmãos enquanto eles estão brincando. Embora os adolescentes executem atividades de cuidado em relação a todos os irmãos menores, são os irmãos mais novos que necessitam de mais atenção e de mais tempo por parte dos irmãos mais velhos. A idade dos irmãos mais novos (caçulas) dos adolescentes do Grupo 1 variou entre um e seis anos.

Verificou-se que as atividades de cuidado dos irmãos menores são geralmente acompanhadas por atividades domésticas, tais como: fazer o café da manhã, lavar a louça do café da manhã, arrumar a cozinha, varrer a sala, fazer o almoço, lavar a louça do almoço, limpar o fogão, limpar a cozinha, fazer o café da tarde, varrer o chão da casa e o do pátio, limpar os quartos, lavar as roupas, estender as roupas, arrumar as cobertas e arrumar as camas.

Os resultados mostraram que as tarefas de cuidado entre irmãos podem ser divididas entre mais de um irmão e que a forma como o cuidado é desempenhado depende do modo como cada família está organizada. A família de If (16a7m) ilustra esta situação. Apesar da mãe de If não trabalhar, ela costuma sair de casa durante as manhãs. Neste período, é If quem assume a responsabilidade pelo cuidado dos oito irmãos menores. À tarde, quando If vai à escola, o irmão seguinte na ordem cronológica $(15 \mathrm{a} 0 \mathrm{~m})$ assume o cuidado, junto com a mãe. Após a escola, If novamente cuida dos irmãos menores, desta vez, compartilhando as tarefas com a mãe.

Da mesma forma, a realização das atividades domésticas depende de como a família está organizada. Na família de Ff (14a11m), por exemplo, as atividades domésticas são divididas entre ela e a irmã de 11 anos, de forma intercalada entre os dias da semana. Em relação às tarefas domésticas, Ff explica: "Tem que limpar o nosso quarto, o da minha mãe, o banheiro e a cozinha. Daí tem que lavar a louça e limpar o fogão à lenha, e passar pano na casa". No entanto, apenas Ff é responsável pelo cuidado das irmãs menores: "Eu cuido pra elas não se machucar, não brigar, é que elas não tem brinquedo, né? Daí elas brincam juntas, daí eu invento alguma coisa pra elas brincar". Assim, no dia em que Ff assume as atividades domésticas, ela precisa organizar-se para, ao mesmo tempo, dar conta também de cuidar das irmãs pequenas. Ff recebe ajuda da mãe para cuidar das irmãs somente quando a mãe não está envolvida com o trabalho do companheiro.

Os relatos do dia de vida mostraram que quando os adolescentes do Grupo 1 são do sexo masculino, surgem algumas diferenças em relação ao desempenho das atividades domésticas e de cuidado se comparados às adolescentes do mesmo grupo. Cm (13a6m) é responsável por levar e buscar os irmãos menores na creche e dar banho neles. Todavia, a única atividade doméstica que ele desempenha é arrumar a própria cama. Mesmo sendo responsável por poucas atividades de cuidado, se comparado aos demais participantes deste grupo, $\mathrm{Cm}$ pode ser considerado responsável por cuidar dos irmãos menores, pois as atividades que ele desempenha são complexas e exigem muita atenção para um menino de 13 anos. Sobre levar os irmãos menores para a creche, $\mathrm{Cm}$ relata: "Sou eu que levo porque eu sou o mais velho. Daí a mãe sabe que eu cuido deles. Não andam atirado na rua... tenho que cuidar a faixa, porque a gente botemos eles parado ali, eles não obedecem a gente... Tem que ficar 24 horas de olho neles".

Embora todos os adolescentes do Grupo 1 frequentem a escola e alguns deles realizem atividades extraclasse, a análise do dia de vida indicou que a assiduidade às atividades escolares está diretamente relacionada ao funcionamento de suas famílias. Esta constatação pode ser exemplificada pelo relato de Ff(14a11m). De acordo com a adolescente, sua mãe, quando precisa sair de casa, lança mão de duas estratégias em relação às filhas pequenas: ou Ff vai junto com a mãe e com as irmãs para cuidá-las, pois caso contrário "elas fazem muita bagunça e a minha mãe não consegue fazer o que tem para fazer" ou Ff fica em casa cuidando das irmãs. Em qualquer uma das situações, Ff falta à escola ou à atividade extraclasse.

A partir dos dados da Tabela 1, pode-se observar que os participantes do Grupo 1 ficaram sem estudar por, pelo menos, um ou dois anos e que muitos apresentam um histórico de até três reprovações. Conforme explicou Bf $(12 \mathrm{a} 9 \mathrm{~m})$ : "Eu rodei mesmo, porque eu tinha que ficar em casa, cuidando dos meus irmãos, porque senão tinha passado rapidinho...". Nenhum destes adolescentes relatou que realiza temas de casa ${ }^{4}$.

As atividades de lazer dos adolescentes do Grupo 1 são as que menos aparecem durante o relato do dia, variando de nenhuma a três atividades. A principal opção de lazer é assistir televisão. Seis participantes relataram que assistem televisão uma vez ao dia, normalmente à noite. Conforme relata If (16a7m): "Depois que tá todo mundo na cama, eu fico lendo um livro com calma, mais calma ainda, até esfriar a cabeça da agitação do dia. Eu pego e leio um livro ou então fico com a televisão ligada, aí desligo a TV e deito". Para If, assistir televisão e ler não são apenas atividades para se divertir. É assim que a adolescente descansa das tarefas realizadas ao longo do dia.

4 Em Porto Alegre, a expressão "tema de casa" refere-se às atividades escolares realizadas pelos alunos em casa. 
Quando questionados sobre o que mais gostam de fazer, os adolescentes do Grupo 1 citaram as seguintes atividades: assistir televisão, olhar desenho, conversar com as amigas, desenhar, escrever poesia, brincar, ler, jogar futebol, visitar parentes, dar comida para as irmãs, cuidar do irmão mais novo, ir para o colégio e trabalhar. Em relação ao momento do dia no qual os adolescentes realizam essas atividades, os dois participantes do sexo masculino relataram que encontram tempo em todos os dias da semana. Entre as participantes do sexo feminino, encontrar tempo depende de uma série de fatores. If $(16 \mathrm{a} 7 \mathrm{~m})$ relata que as atividades de que mais gosta são assistir desenho ou filme na televisão e cuidar do irmão menor e, para tal, ela organiza-se da seguinte maneira: "Eu primeiro faço o que tenho pra fazer, minha obrigação. Aí termino, pego todo mundo (todos os irmãos) e boto todo mundo sentadinho no sofá e eu fico junto lá olhando também, aí eu fico com eles todos". O relato indica que a alternativa encontrada por ela para poder, ao mesmo tempo, assistir televisão e cuidar do irmão menor é organizar todas as tarefas, de modo que ela consiga conciliar o término das atividades domésticas com o banho dos irmãos. Assim, uma vez que os irmãos já estão todos de banho tomado e que as atividades domésticas já foram realizadas, If pode desfrutar um momento de lazer.

\section{Atividades do Grupo 2}

As atividades de cuidado dos irmãos menores referem-se "a ajudar a mãe a reparar os irmãos" nas seguintes situações: almoço, ida e volta da escola e da atividade extraclasse, café da tarde, banho e quando os irmãos menores estão brincando. Neste grupo, diferentemente do que ocorreu no Grupo 1, as atividades de cuidado dizem respeito aos irmãos menores em geral e não apenas aos caçulas. $\mathrm{O}$ cuidado que estes adolescentes dispensam a seus irmãos menores não interfere, porém, em suas outras atividades. Por exemplo, Lf (12a6m) refere que ajuda a mãe somente quando a irmã mais velha ainda não chegou em casa. Quando questionada se ajuda a mãe a servir o café da manhã para os irmãos menores, Df (13a10m) responde que "À̀s vezes, sim, às vezes, não, porque, dia de semana, não dá pra mim ajudar a dar café porque eu tenho colégio de manhã. Quando não tem aula, eu fico em casa, daí eu ajudo a minha mãe. Às vezes, quando me dá preguiça, aí eu não ajudo".

Os demais participantes que relataram atividades de cuidado estão envolvidos com o deslocamento de alguns de seus irmãos menores para as atividades escolares. Nestas famílias, os irmãos mais velhos levam os mais novos de acordo com o lugar para o qual cada um deve ir, ou levam e buscam em um turno no qual estão disponíveis. Por exemplo, durante a manhã, $\operatorname{Pf}(15 \mathrm{a} 7 \mathrm{~m})$ leva a irmã pequena para a creche enquanto está indo para sua atividade extraclasse. À tarde, Pf (15a7m) explica que: "Daí 13h, eu levava ela (a irmã) pro colégio. Depois, eu chegava em casa, eu ia na minha vó, ficava em casa, jogando videogame, fazendo alguma coisa em casa, depois, quando chegava o horário dela soltar do colégio, eu buscava ela e depois vinha em casa e me arrumava pro colégio".
Além de ajudar a cuidar dos irmãos menores, os participantes do Grupo 2 também realizam atividades domésticas, tais como: lavar as próprias roupas e ajudar a mãe a arrumar a casa, conforme relata Qm (13a11m): "Eu ajudo a minha mãe a lavar a louça, limpar o pátio, varrer o chão, arrumar as camas" e complementa dizendo: "ajudo a cuidar dos meus irmãos, pra eles não brigarem, não se machucarem". Os relatos destes adolescentes indicam que eles apenas ajudam nas tarefas cotidianas, ao invés de serem responsáveis por sua execução.

Os dados da Tabela 1 mostram que a escolaridade dos participantes do Grupo 2 também é baixa. Observando-se a idade, a série e o número de reprovações é possível verificar que os participantes deste grupo ingressaram no Ensino Fundamental com mais de sete anos de idade. Em relação ao número de reprovações, os adolescentes do Grupo 2 são menos repetentes do que os do Grupo 1. Quatro adolescentes deste grupo referiram que estudam ou fazem temas de casa em algum momento do dia.

Em relação às atividades de lazer os adolescentes do Grupo 2 citaram: assistir televisão, escrever poesias e músicas, desenhar, jogar videogame, brincar com os irmãos, conversar com amigas e navegar na internet. Quando questionados sobre o que mais gostam de fazer, os adolescentes citaram: conversar com as amigas, ver clipe, assistir televisão, ir para o colégio, descansar, desenhar, fazer esportes, ir à casa da avó, sair de ônibus, estudar e brincar com os irmãos. Todos os participantes relataram que realizam as atividades que mais gostam em todos os dias da semana.

\section{Atividades do Grupo 3}

Alguns adolescentes deste grupo ajudam suas mães em atividades domésticas específicas, tais como: lavar a louça, varrer o pátio e lavar as próprias roupas. Conforme explica $\mathrm{Tf}(16 \mathrm{a} 10 \mathrm{~m})$ : "Lavar as minhas roupa, quem lava sou eu, porque não gosto que a minha mãe lave no tanquinho e nem na máquina, porque enche de bolinha... mas, nas tarefas de casa, é difícil, lá de vez em quando, porque é difícil eu ficar em casa, né? De vez em quando, eu varro, passo uma vassoura na casa, mas nada pesado". Pelo relato de Tf, pode-se perceber que ela eventualmente ajuda a sua mãe, mas isso não é uma obrigação nem prejudica suas atividades escolares e de lazer.

Os participantes do Grupo 3 são os que apresentam o melhor nível de escolaridade, embora ainda seja baixo. Nos dados da Tabela 1, observa-se que os adolescentes deste grupo também ingressaram no Ensino Fundamental com, pelo menos, um ano de atraso. Uma adolescente deste grupo referiu que estuda ou faz temas de casa em algum momento do dia.

No que se refere às atividades de lazer, os adolescentes do Grupo 3 relataram: assistir televisão, escrever no diário, escrever músicas e poesias, visitar parentes, ir na casa de amigas, jogar bola e ler. Quando questionados sobre o que mais gostam de fazer, os adolescentes citaram: jogar bola, jogar videogame, conversar com amigas, escrever poesia e música e cantar na igreja. Todos os adolescentes deste grupo disseram que realizam essas atividades, no mínimo, duas vezes ao dia. 


\section{Discussão}

Em relação às atividades de cuidado dos irmãos do Grupo 1, foi possível observar que, entre todos os irmãos menores, são os mais novos que necessitam de mais atenção. Além disso, é cuidando deles que os adolescentes gastam a maior parte de seu tempo. Estes resultados evidenciam que o cuidado formal entre irmãos também ocorre em sociedades industrializadas (East, 2010; Furman \& cols., 1979) e não apenas em sociedades agrárias, conforme propõe Cicirelli (1994). Em consonância com Tudge (2008) pode-se pensar que existe uma heterogeneidade de práticas e valores educativos dentro de uma mesma sociedade.

A realização de atividades domésticas por irmãos que cuidam de seus irmãos mais novos também foi descrita em estudos desenvolvidos em diferentes culturas (Bezerra, 2006; Ferreira, 1991; Dahlblom \& cols., 2009; Kosminsky \& Santana, 2006; Poletto \& cols., 2004; Rios-Gonzáles, 1994; Romich, 2007; Zukow, 2002). No entanto, as tarefas domésticas realizadas pelos adolescentes do Grupo 1 não se restringem a ajudar em atividades simples do dia-a-dia. Eles executam tarefas que exigem, além de esforço físico, bastante atenção.

Os resultados revelaram ainda que as participantes do sexo feminino realizam tanto atividades de cuidado quanto domésticas, enquanto que os do sexo masculino desempenham mais atividades de cuidado dos irmãos menores do que tarefas domésticas. Nestes casos, as tarefas domésticas ficam por conta de uma irmã menor ou da própria mãe. O estudo realizado por Kosminsky e Santana (2006) também encontrou diferenças em relação ao sexo dos participantes nessa mesma direção. Isto indica que, apesar de filhos do sexo masculino também assumirem a responsabilidade por algumas atividades de cuidado dos irmãos menores, as atividades domésticas ainda são preferencialmente desempenhadas por outra integrante da família do sexo feminino. Tal constatação confirma a pesquisa de Bezerra (2006), cujos resultados indicam que, em função da cultura de que atividade doméstica é uma tarefa feminina, os efeitos do trabalho realizado no próprio domicilio são mais vivenciados pelas meninas do que pelos meninos mais velhos.

Alguns estudos mostram que a maioria das famílias de baixa renda são monoparentais (Silveira, Falcke \& Wagner, 2000). O fato de mais da metade das famílias dos participantes deste estudo ser monoparental confirma os dados da literatura. Entre as famílias com esta configuração específica, a maioria é chefiada por mulheres. Tal constatação leva a supor que as mulheres vêm desempenhando cada vez mais funções na família, consideradas fundamentais para sua manutenção e organização (Amazonas \& cols., 2003; East, Weisner \& Slonim, 2009). Esta tendência foi observada nos grupos 1 e 2: cerca de metade das famílias destes grupos são monoparentais. Não por acaso, são nessas famílias que o cuidado entre irmãos está presente de alguma forma.

A análise do dia de vida dos participantes do Grupo 1 mostra também que as tarefas de cuidado dos irmãos mais novos podem ser divididas entre mais de um irmão, de acordo com a forma na qual a família está organizada. Este resultado vai ao encontro dos estudos de Zukow (2002), segundo os quais um filho específico pode ser responsável pelo cuidado de um irmão menor e, ao mesmo tempo, acatar e receber orientação de um irmão ainda mais velho do que ele. Isto parece ilustrar a lógica da solidariedade presente nas famílias de baixa renda descrita por Amazonas e cols. (2003) como a necessidade de todos os membros da família participarem da manutenção do grupo. Pode-se pensar que este tipo de organização familiar ocorra em função das modificações socioeconômicas e culturais que vêm alterando os vínculos familiares na sociedade contemporânea, como, por exemplo, o advento das famílias monoparentais e reconstituídas. Deste modo, os membros das famílias estão sendo levados a assumir novos papéis e posições e a conviver com novos arranjos familiares.

Na realidade brasileira, outro fator deve ser considerando para entender por quê crianças e adolescentes assumem papeis de cuidadores de seus irmãos: a falta de vagas nas escolas públicas de educação infantil. Neste sentido, pesquisas recentes alertam para o fato de que existe uma discrepância entre o número de crianças com idade para frequentar creches e o número real de vagas disponíveis principalmente em relação às crianças de zero a três anos de idade (Freitas, Shelton \& Sperb, 2009; Freitas, Shelton \& Tudge, 2008). Além disso, sabe-se que muitas creches da rede pública priorizam crianças cujas mães trabalham fora de casa, excluindo do sistema de educação infantil as famílias em maior situação de vulnerabilidade social, ou seja, aquelas que sobrevivem apenas com os benefícios de programas sociais.

Os participantes do Grupo 2 também realizam atividades de cuidado dos irmãos menores. Todavia, a intensidade e o nível de responsabilidade do cuidado por eles realizado difere totalmente daqueles dos participantes do Grupo 1 . Isto acontece porque, para os participantes do Grupo 1, cuidar dos irmãos mais novos é a prioridade, enquanto que os adolescentes do Grupo 2 simplesmente ajudam a mãe a "reparar os irmãos" em alguns momentos do dia. Além disso, comparando-se as tarefas que os participantes dos dois primeiros grupos desempenham, pode-se observar que: (a) os afazeres realizados pelos adolescentes do Grupo 2 são mais amenos que os realizados pelos do Grupo 1 e (b) por não serem consideradas uma obrigação, essas tarefas não interferem significativamente nas outras atividades desses adolescentes. Estes dados vão ao encontro do estudo de Lamarão (2002), segundo o qual as tarefas domésticas realizadas por crianças e adolescentes compatíveis com seu desenvolvimento físico e psicossocial, isto é, que são complementares ao trabalho adulto, são uma forma de mostrar reciprocidade, respeito e obediência ao grupo familiar.

Pode-se dizer que em relação tanto às tarefas domésticas quanto às de cuidado, os adolescentes do Grupo 2 são apenas coadjuvantes. Isto mostra que nas famílias deste grupo, a mãe assume o controle da casa, solicitando ajuda aos filhos apenas quando necessário. Assim, entre essas famílias, as fronteiras entre os membros parecem estar claras e os papéis bem delimitados, uma vez que não há sobreposição nem inversão entre os papéis de mãe e de filho.

No que diz respeito aos participantes do Grupo 3, os resultados mostram que eles também realizam atividades domésticas. Contudo, os adolescentes deste grupo citaram um menor número dessas atividades e relataram que realizam tarefas domésticas por iniciativa própria. Assim, foi possível 
observar que, se a mãe não costuma pedir ajuda, os próprios participantes oferecem auxílio.

A análise dos relatos dos adolescentes quanto às atividades de cuidado dos irmãos e das atividades domésticas revela que: (a) no Grupo 1, as atividades de cuidado dos irmãos menores são realizadas tanto por meninas quanto por meninos, enquanto que as atividades domésticas são realizadas predominantemente pelas meninas; (b) os adolescentes do Grupo 2 ajudam suas mães tanto nas atividades de cuidado dos irmãos como nas atividades domésticas, independentemente do sexo e (c) embora não realizem nenhum tipo de atividade de cuidado em relação aos irmãos, os participantes do Grupo 3 realizam algumas atividades domésticas. Desta forma, evidencia-se que, independentemente da ocorrência ou não de cuidado entre irmãos, os participantes do estudo ajudam, em alguma medida, na realização das tarefas domésticas. Esta constatação confirma o estudo de Amazonas e cols. (2003), segundo o qual, em famílias de baixa renda, é preciso que todos os seus membros participem da manutenção do grupo para garantir a qualidade de vida de cada um.

As fronteiras entre o Grupo 1 e o Grupo 2 não são fixas. Gm (14a11m), por exemplo, seria incluído no Grupo 2, pois ele, geralmente, apenas ajuda a mãe a cuidar dos irmãos. No entanto, Gm (14a11m) assumiu o papel de responsável por todos os seus quatro irmãos mais novos durante aproximadamente três meses, em função de sua mãe estar hospitalizada. Como no período no qual a entrevista foi realizada a mãe de Gm ainda estava internada e, portanto, ele estava assumindo o cuidado dos irmãos menores, ele foi incluído no Grupo 1. Esta situação ilustra que pode haver uma flutuação entre os papéis assumidos pelos adolescentes, em função de circunstâncias da vida, as quais podem ser mais ou menos duráveis.

Todos os adolescentes do estudo frequentam a escola e cursam o Ensino Fundamental. Este resultado confirma a pesquisa do IBGE (2007), segundo a qual o Ensino Fundamental está quase universalizado no país. Todavia, embora os participantes frequentem a escola, o número de reprovações é alto, o que explica o baixo nível de escolaridade da amostra.

Assim, os resultados desta pesquisa apontam na mesma direção de um estudo da UNICEF (2002), segundo o qual o índice de distorção entre a idade e a série escolar frequentada é alto entre adolescentes de baixa renda. Mesmo entre os poucos participantes que nunca reprovaram, a relação entre a série que eles frequentam e a sua idade não corresponde ao esperado. Desta forma, pode-se pensar que o nível socioeconômico das famílias deste estudo é um fator determinante para a defasagem escolar dos participantes. Estes dados confirmam pesquisas segundo as quais a renda das famílias está relacionada tanto ao acesso das crianças à educação infantil quanto ao momento de ingresso dos adolescentes no Ensino Médio (IBGE, 2007). De acordo com os critérios do IBGE (2007), todos os adolescentes do Grupo 1 são considerados defasados em relação a sua escolaridade, o que corrobora dados da literatura de que o trabalho realizado no ambiente domiciliar prejudica o rendimento escolar dos estudantes (Bezerra, 2006).

Pesquisas (Burton, 2007; Dahlblom \& cols., 2009; East $\&$ Weisner, 2009) mostram que crianças e adolescentes que assumem uma carga muito grande de responsabilidades em relação às suas famílias, e que, consequentemente, extrapo- lam os limites da mera colaboração nas tarefas domésticas, sacrificam seu desempenho escolar e sofrem prejuízo em seu desenvolvimento educacional. Marshall e cols. (1997) salientam que, quando as demandas de cuidado sobre o primogênito se tornam muito excessivas, elas podem interferir no tempo que ele dedica às atividades escolares. Todavia, os dados deste estudo evidenciam que não apenas o primogênito, mas o irmão mais velho que mora em casa assume a responsabilidade pelo cuidado dos demais irmãos.

No que diz respeito à defasagem escolar encontrada no Grupo 1, pode-se pensar que: (a) estes adolescentes têm que faltar muitos dias de aula em função da responsabilidade pelo cuidado de seus irmãos menores e de tarefas domésticas; (b) muitos adolescentes evadiram da escola, principalmente, nas séries iniciais do Ensino Fundamental pelo mesmo motivo; (c) uma vez que realizam diariamente atividades de cuidado e tarefas domésticas, estes adolescentes não têm tempo suficiente para se dedicarem às tarefas escolares.

Em relação à escolaridade, os participantes do Grupo 2 apresentam menos reprovações do que os do Grupo 1 e metade dos adolescentes do Grupo 3 está defasado. Entretanto, nenhum participante do Grupo 2 ou do Grupo 3 referiu o cuidado dos irmãos ou a realização de atividades domésticas como motivo para suas reprovações. De qualquer forma, o número de repetências dos adolescentes dos três grupos chama atenção. Este dado confirma análise realizada pelo IBGE (2007), segundo o qual a defasagem escolar é um dos principais problemas do sistema de ensino brasileiro.

Quanto às atividades extraclasse, pode-se dizer que os adolescentes do Grupo 2 conseguem aproveitar melhor os recursos da comunidade, quando comparados aos adolescentes do Grupo 1. Além disso, quase metade dos participantes refere que estuda ou faz temas de casa em algum momento do dia. Estes dados indicam que o fato dos adolescentes desse grupo ajudarem a cuidar de seus irmãos menores não interfere na realização das suas atividades escolares diárias. Quando comparados os três grupos, são os adolescentes do Grupo 3 que mais usufruem dos recursos da comunidade em relação a atividades extraclasse. Desta forma, as instituições escolares estimulam não apenas a aprendizagem, mas também, o reforço de habilidades sociais e emocionais, fundamentais para o desenvolvimento (Poletto \& cols., 2004).

Os resultados sugerem ainda que, de modo geral, os participantes deste estudo realizam atividades de lazer pouco diversificadas e que assistir à televisão é a principal opção de lazer. Estes dados confirmam pesquisas segundo as quais adolescentes de baixa renda têm poucas alternativas de lazer e pouca diversificação do uso de seu tempo livre (UNICEF, 2002; Sarriera, Tatim, Coelho \& Büsker, 2007). Embora existam diferenças entre os grupos, é durante os finais de semana que os participantes costumam realizar mais atividades de lazer fora de casa. Estes resultados também confirmam a literatura sobre o assunto. De acordo com Sarriera e cols. (2007), adolescentes destinam mais tempo do fim de semana para atividades fora de casa na companhia de amigos, as quais são realizadas, sobretudo, na própria comunidade.

Entre todos os participantes do estudo, são aqueles do Grupo 1, principalmente as adolescentes do sexo feminino, que menos realizam atividades de lazer. Estes dados estão de acordo com as conclusões do estudo da UNICEF (2002), 
segundo o qual meninas envolvidas com tarefas domésticas se queixam mais de falta de tempo para as atividades de lazer. Os adolescentes do sexo masculino têm mais oportunidades de realizar esse tipo de atividade, uma vez que não assumem concomitantemente as tarefas domésticas.

Para as adolescentes do Grupo 1, o lazer parece confundir-se com descanso. Isto ocorre porque o cuidado dos irmãos menores e as atividades domésticas ocupam praticamente todo o dia. Assim, encontrar tempo para o lazer e o descanso depende de uma série de fatores. Para que as participantes do Grupo 1 consigam um momento para o lazer/descanso, é preciso que todas as tarefas domésticas do dia tenham sido realizadas e, além disso, que a mãe esteja em casa, ou que a adolescente responsável pelo cuidado saia de casa.

No Grupo 1, existe uma diferença importante entre as atividades de lazer citadas pelos participantes, ao descreverem um dia típico de suas vidas, e as atividades de lazer que eles mais gostam de fazer. Enquanto foram citadas, em média, três atividades de lazer na descrição do dia de vida, os participantes referiram treze atividades como as que mais gostam de fazer. Estes dados sugerem que, apesar destes participantes demonstrarem interesse por várias atividades lúdicas, na realidade, eles realizam poucas atividades de lazer ao longo de um dia típico de suas vidas.

Brincar, olhar desenho e sair para visitar parentes foram atividades citadas pelos participantes do Grupo 1 como aquelas que eles mais gostam de fazer. Este resultado leva a supor que, apesar de desempenharem o papel que seria de um adulto, quando assumem atividades domésticas e de cuidado dos irmãos menores, estes adolescentes (principalmente os do sexo feminino) ainda sentem falta de atividades que realizavam na infância ou que, talvez, nem tenham tido a chance de realizar.

Os resultados indicam que alguns participantes têm mais tempo para o lazer durante o final de semana. Pode-se pensar que isso acontece porque, aos finais de semana, os adolescentes não precisam ir à escola e suas mães assumem os cuidados dos filhos e das tarefas domésticas, liberando o filho cuidador. Entretanto, é importante salientar que nem todos os participantes do Grupo 1 compartilham esta realidade.

Quanto aos participantes do Grupo 2 e do Grupo 3, eles não sofrem prejuízo em suas atividades de lazer. Ao longo do dia, existem momentos de intervalo entre uma atividade e outra, os quais são ocupados com alguma atividade de lazer. Nestes grupos, a maior parte das atividades citadas pelos participantes como as que mais gostam também foram referidas em um dia típico de suas vidas.

No que diz respeito ao que mais gostam de fazer quando tem tempo livre, as respostas dos participantes foram mais homogêneas nos três grupos. Isto indica que, apesar das diferenças nas rotinas dos participantes, em função da ocorrência ou não da situação de cuidado entre irmãos e de atividades domésticas, estes adolescentes se interessam e gostam de atividades de lazer semelhantes.

\section{Considerações Finais}

As atividades de cuidado dos irmãos menores e as tarefas domésticas acarretam prejuízos no desempenho escolar do adolescente que assume a função de cuidador. Apesar de estarem matriculados na escola, esses adolescentes nem sempre são assíduos. Além disso, a sua rotina não permite que eles estudem ou façam temas de casa. Não há tempo também para atividades de lazer. Entretanto, entende-se, como Ferreira (1991), East (2010) e East, Weisner e Slonim (2009), que apenas estudos longitudinais possam verificar as consequências a longo prazo da situação de cuidados formais no desenvolvimento de crianças e adolescentes - tanto dos que cuidam quanto dos que são cuidados.

A entrevista semiestruturada sobre o dia de vida possibilitou a investigação de assuntos que foram abordados pelos adolescentes, através da descrição da rotina particular de cada um deles. Além disso, essa entrevista revelou-se um instrumento fundamental neste estudo, pois somente através dela foi possível verificar se o adolescente indicado como irmão cuidador era, efetivamente, um adolescente responsável pelo cuidado de seus irmãos menores.

Apesar deste estudo ter sido realizado com apenas 20 participantes, espera-se que os resultados possam ajudar os profissionais que trabalham com famílias a entender um pouco mais sobre a situação de cuidado entre irmãos e a motivá-los a olhar com atenção para as relações entre irmãos. Sugere-se que outras pesquisas sejam realizadas com famílias nas quais esteja presente a situação de cuidado formal entre irmãos. Em estudos futuros, seria importante incluir não apenas o irmão cuidador, mas também os irmãos menores e suas mães.

\section{Referências}

Amazonas, M. C. L. de A., Damasceno, P. R., Terto L. de M. de S., \& Silva, R. R. da (2003). Arranjos familiares de crianças das camadas populares. Psicologia em Estudo, 8, 11-20.

Bezerra, M. E. G. (2006). O trabalho infantil afeta o desempenho escolar no Brasil? Dissertação de Mestrado, Universidade de São Paulo, Piracicaba.

Burton, L. (2007). Childhood adultification in economically disadvantaged families: A conceptual model. Family Relations, 56, 329-345.

Carreño, C. M., \& Avila, S. C. (2002). El vínculo de apego entre hermanos: Um estudio exploratório con ninõs colombianos de estrato bajo. Suma Psicologica, 9, 107-132.

Cicirelli, V. G. (1994). Sibling relationships in cross-cultural perspective. Journal of Marriage and the Family, 56, 7-20.

Conger, K. J., Stocker, C., \& McGuire, S. (2009). Sibling socialization: The effects of stressful life events and experiences. Em L. Kramer \& K. J. Conger (Eds.), Siblings as agents of socialization: New Directions for Child and Adolescent Development (pp. 45-60). San Francisco: Jossey-Bass.

Dahlblom, K., Herrara, A. R., Pena, R., \& Dahlgren, L. (2009). Home Alone: Children as caretakers in León, Nicarágua. Children \& Society, 23, 43-56.

Dunn, J. (1983). Sibling relationships in early childhood. Child Development, 54, 787-811.

East, P. L. (2010). Children's provision of family caregiving: Benefit or burden? Child Development Perspectives 4, 55-61.

East, P. L., \& Weisner, T. S. (2009). Mexican American adolescents' family caregiving: Selection effects and longitudinal associations with adjustment. Family Relations, 58, 562-577. 
East, P. L., Weisner, T. S., \& Slonim, A. (2009). Youths' caretaking of their adolescent sisters' children: Results from two longitudinal studies. Journal of Family Issues, 30, 1671-1697.

Ferreira, E. A. P. (1991). Irmãos que cuidam de irmãos na ausência dos pais: Um estudo sobre desempenho em tarefas domésticas e interação ente irmãos. Dissertação de Mestrado, Universidade de Brasília, Brasília.

Freitas, L. B. L., Shelton, T. L., \& Sperb, T. M. (2009). Conceptions of early childhood care and education in Brazil. Em: M. Fleer, M. Hedegaard \& J. Tudge. (Eds.), World Yearbook of Education 2009 - Childhood studies and the impact of globalization: Policies and practices at global and local levels (pp. 279-291). London: Routledge.

Freitas, L. B. L., Shelton, T. L., \& Tudge, J. R. H. (2008). Conceptions of US and Brazilian early childhood care and education: A historical and comparative analysis. International Journal of Behavioral Development, 32, 161-170.

Fulighi, A. J., Hughes, D. L., \& Way, N. (2009). Ethnicity and immigration. Em R. M. Lerner \& L. Steinberg (Eds.), Handbook of Adolescent Psychology: Vol 3. Contextual influences on adolescent development (pp. 527-569). New Jersey: Wiley. Retirado de http://books.google.com/books

Furman, W., Rahe, D., \& Hartup, W. (1979). Rehabilitation of socially withdrawn preschool children trough mixed-aged and same-age socialization. Child Development, 50, 915-922.

Hafford, C. (2010). Sibling caretaking in immigrant families: Understanding cultural practices to inform child welfare practice and evaluation. Evaluation and Program Planning, 33, 294-302.

Instituto Brasileiro de Geografia e Estatística. (2007). Síntese de indicadores sociais: Uma análise das condições de vida da população brasileira. Estudos e Pesquisas Informação Demográfica e Socioeconômica número 21. Retirado de http:// www.ibge.com.br/home/estatistica/populacao/condicaodevida/ indicadoresminimos/sinteseindicsociais2007/default.shtm

Kosminsky, E. V., \& Santana, J. N. (2006). Crianças e jovens e o trabalho doméstico: A construção social do feminino. Sociedade e Cultura, 9, 227-236.

Lamarão, M. L. N. (2002). Trabalho infantil doméstico: O lado oculto da exploração de mão-de-obra infanto-juvenil. Retirado de http://www2.ufpa.br/gepia/Arquivos/Artigo_TID01.pdf

Laville, C., \& Dionne, J. (1999). A construção do saber. Porto Alegre: Artmed.

Lordelo, E. R., \& Carvalho, A. M. A. (1989). Comportamento de cuidado entre crianças: Uma revisão. Psicologia: Teoria e Pesquisa, 5, 1-19.

Lordelo, E. R., \& Carvalho, A. M. A. (1999). Um estudo naturalístico do comportamento de cuidado entre crianças préescolares. Biotemas, 12, 7-30.

Marshall, N. L., Garcia-Coll, C., Marx, F., McCartney, K., Keefe, N., \& Ruh, J. (1997). After-school time and children's behavioral adjustment. Merrill-Palmer Quarterly, 43, 497- 514.

Perez, A. P. (2002). O filho primogênito: Suas características e seus relacionamentos no contexto familiar. Em A. Wagner (Org.), Família em cena: Tramas, dramas e transformações (pp. 113131). Petrópolis: Vozes.

Pires, S., Matos, A., Cerqueira, M., Figueiredo, D., \& Souza, L. (2004). Retratos da vida das famílias multiproblemáticas. Revista Serviço Social e Sociedade, 80, 5-32.
Poletto, M., Wagner, T. M. C., \& Koller, S. H. (2004). Resiliência e desenvolvimento infantil de crianças que cuidam de crianças: Uma visão em perspectiva. Psicologia: Teoria e Pesquisa, 20, 241-250.

Romich, J. L. (2007). Sharing the work: mother-child relationships and household management. Journal of Early Adolescence, 27 (2), 92-222.

Rios-Gonzáles, J. (1994). Manual de orientación y terapia familiar. Madrid: Instituto de Ciencias del Hombre.

Sarriera J. C., Tatim, D. C., Coelho, R. P. S., \& Büsker, J. (2007). Uso do tempo livre por adolescentes de classe popular. Psicologia Reflexão e Crítica, 20, 361-367.

Silveira, S. C. da, Falcke, D., \& Wagner, A. (2000). A representação gráfica de meninos institucionalizados. Artigo apresentado no $2^{\circ}$ Congresso da Sociedade Brasileira de Rorschach e outros métodos projetivos, Porto Alegre, Brasil.

Silveira, L. M. O. B. (2002). O relacionamento fraterno e suas características ao longo do ciclo vital. Em A. Wagner (Org.), Família em cena: Tramas, dramas e transformações (pp. 93112). Petrópolis: Vozes.

Stewart, R. B., \& Marvin, R. S. (1984). Sibling relations: The role of conceptual perspective-taking in the ontogeny of sibling. Child development, 55, 1322-1332.

Szinovacz, M. E. (2007). Children in caregiving families. Em M. E. Szinovacz \& A. Davey (Eds.), Caregiving contexts: Cultural, familial and societal implications (pp. 161-192). Retirado de http://books.google.com/books

Teti, D. M. (2001). Retrospect and prospect in the psychologycal study of sibling relationship. Em J. P. McHale \& W. S. Grolnick (Eds.), Retrospect and prospect in the psychological study of families (pp.193-224). Mahwah: Lawrence Erlbaum Associates. Retirado de http://books.google.com/books

Tudge, J. (2008). The everyday lives of young children: Culture, class, and childrearing in diverse societies. New York: Cambridge University Press.

United Nations Children Fund. (2002). A voz da adolescência. Retirado de http://www.unicef.org/brazil/pt/resources_10282. htm

Weisner, T. S. (1987). Socialization for parenthood in sibling caretaking societies. Em J. B. Lancaster \& J. Altmann (Eds.), Parenting across the life span: Biosocial dimensions (pp. 237-270). Hawthorne, NY: Aldine. Retirado de http://books. google.com/books

Weisner, T. S., \& Gallimore, R. (1977). My brother's keeper: Child and sibling caretaking. Current Anthropology, 18, 169-190.

Zukow, P.G. (2002). Sibling Caregiving. Em M. H. Bornstein (Ed.) Handbook of parenting: Vol. 3. Being and becoming a parent (pp. 253-286). Mahwah: Lawrence Erlbaum Associates. Retirado de http://books.google.com/books

Recebido em 13.11.08 Primeira decisão editorial em 28.09.09 Versão final em 15.07.10 Aceito em 14.10.10 